\title{
Rapid subduction in the deep North Western Mediterranean
}
J. A. Aguilar ${ }^{1}$, A. Albert ${ }^{2}$, M. Anghinolfi ${ }^{3}$, G. Anton ${ }^{4}$, S. Anvar ${ }^{5}$, M. Ardid ${ }^{6}$, A. C. Assis Jesus ${ }^{7}$, T. Astraatmadja ${ }^{7,35}$, J.-J. Aubert ${ }^{8}$, R. Auer ${ }^{4}$, B. Baret ${ }^{9}$, S. Basa ${ }^{10}$, M. Bazzotti $^{11,12}$, V. Bertin ${ }^{8}$, S. Biagi ${ }^{11,12}$, C. Bigongiari ${ }^{1}$, M. Bou-Cabo ${ }^{6}$, M. C. Bouwhuis ${ }^{7}$, A. Brown ${ }^{8}$, J. Brunner ${ }^{8,}{ }^{*}$, J. Busto $^{8}$, F. Camarena ${ }^{6}$, A. Capone ${ }^{13,14}$, G. Carminati ${ }^{11,12}$, J. Carr $^{8}$, D. Castel $^{2}$, E. Castorina ${ }^{15,16}$, V. Cavasinni ${ }^{15,16}$, S. Cecchini ${ }^{12,17}$, Ph. Charvis ${ }^{18}$, T. Chiarusi ${ }^{12}$, M. Circella $^{19}$, R. Coniglione ${ }^{20}$, H. Costantini ${ }^{3}$, N. Cottini ${ }^{21}$, P. Coyle $^{8}$, C. Curtil ${ }^{8}$, G. De Bonis ${ }^{13,14}$, M. P. Decowski ${ }^{7}$, I. Dekeyser ${ }^{22}$, A. Deschamps ${ }^{18}$ C. Distefano ${ }^{20}$, C. Donzaud ${ }^{9,23}$, D. Dornic ${ }^{8,1}$, D. Drouhin ${ }^{2}$, T. Eberl ${ }^{4}$, U. Emanuele ${ }^{1}$, J.-P. Ernenwein ${ }^{8}$, S. Escoffier ${ }^{8}$, F. Fehr $^{4}$, V. Flaminio ${ }^{15,16}$, K. Fratini ${ }^{24,3}$, U. Fritsch ${ }^{4}$, J.-L. Fuda ${ }^{22}$, G. Giacomelli ${ }^{11,12}$, J. P. Gómez-González ${ }^{1}$, K. Graf ${ }^{4}$, G. Guillard ${ }^{25}$, G. Halladjian ${ }^{8}$, G. Hallewell ${ }^{8}$, H. van Haren ${ }^{26}$, A. J. Heijboer ${ }^{7}$, Y. Hello ${ }^{18}$, J. J. Hernández-Rey ${ }^{1}$, J. HößI ${ }^{4}$, and M. de Jong ${ }^{7,35}$

Rapid subduction in the deep North

Western

Mediterranean

J. A. Aguilar et al.

\section{Title Page}

\section{Full Screen / Esc}

Printer-friendly Version

Interactive Discussion 
OSD

N. Kalantar-Nayestanaki ${ }^{27}$, O. Kalekin ${ }^{4}$, A. Kappes ${ }^{4}$, U. Katz ${ }^{4}$, P. Kooijman ${ }^{7,28,29}$, C. Kopper ${ }^{4}$, A. Kouchner ${ }^{9}$, W. Kretschmer ${ }^{4}$, R. Lahmann ${ }^{4}$, P. Lamare ${ }^{5}$, G. Lambard ${ }^{8}$, G. Larosa ${ }^{6}$, H. Laschinsky ${ }^{4}$, D. Lefèvre ${ }^{22}$, G. Lelaizant ${ }^{8}$, G. Lim $^{7,29}$, D. Lo Presti ${ }^{30}$, H. Loehner ${ }^{27}$, S. Loucatos ${ }^{21}$, F. Lucarelli ${ }^{13,14}$, K. Lyons ${ }^{25}$, S. Mangano ${ }^{1}$, M. Marcelin ${ }^{10}$, A. Margiotta ${ }^{11,12}$, J. A. Martinez-Mora ${ }^{6}$, G. Maurin ${ }^{21}$, A. Mazure ${ }^{10}$, M. Melissas ${ }^{8}$, T. Montaruli ${ }^{19,31}$, M. Morganti ${ }^{15,16}$, L. Moscoso ${ }^{21,9}$, H. Motz ${ }^{4}$ C. Naumann ${ }^{21}$, M. Neff ${ }^{4}$, R. Ostasch ${ }^{4}$, G. Palioselitis ${ }^{7}$, G. E. Păvălaş ${ }^{32}$, P. Payre $^{8}$, J. Petrovic ${ }^{7}$, P. Piattelli ${ }^{20}$, N. Picot-Clemente ${ }^{8}$, C. Picq ${ }^{21}$, R. Pillet ${ }^{18}$, V. Popa ${ }^{32}$, T. Pradier $^{25}$, E. Presani ${ }^{7}$, C. Racca ${ }^{2}$, A. Radu $^{32}$, C. Reed ${ }^{8,7}$, G. Riccobene ${ }^{20}$, C. Richardt ${ }^{4}$, M. Rujoiu ${ }^{32}$, G. V. Russo ${ }^{30}$, F. Salesa ${ }^{1}$, F. Schoeck ${ }^{4}$, J.-P. Schuller ${ }^{21}$, R. Shanidze ${ }^{4}$, F. Simeone ${ }^{14}$, M. Spurio ${ }^{11,12}$, J. J. M. Steijger ${ }^{7}$, Th. Stolarczyk ${ }^{21}$, C. Tamburini ${ }^{22}$, L. Tasca ${ }^{10}$, I. Taupier-Letage ${ }^{34, * *}$, S. Toscano ${ }^{1}$, B. Vallage ${ }^{21}$, V. Van Elewyck ${ }^{9}$, M. Vecchi ${ }^{13}$, P. Vernin ${ }^{21}$, G. Wijnker ${ }^{7}$, E. de Wolf ${ }^{7,29}$, H. Yepes ${ }^{1}$, D. Zaborov ${ }^{33}$, J. D. Zornoza ${ }^{1}$, and J. Zúñiga ${ }^{1}$

${ }^{1}$ IFIC - Instituto de Física Corpuscular, Edificios Investigación de Paterna, CSIC - Universitat de València, Apdo. de Correos 22085, 46071 Valencia, Spain

${ }^{2}$ GRPHE - Institut universitaire de technologie de Colmar, 34 rue du Grillenbreit BP 50568 68008 Colmar, France

${ }^{3}$ Dipartimento di Fisica dell'Università e Sezione INFN, Via Dodecaneso 33, 16146 Genova, Italy

${ }^{4}$ Friedrich-Alexander-Universität Erlangen-Nürnberg, Erlangen Centre for Astroparticle Physics, Erwin-Rommel-Str. 1, 91058 Erlangen, Germany

${ }^{5}$ Direction des Sciences de la Matière - Institut de recherche sur les lois fondamentales de l'Univers Service d'Electronique des Détecteurs et d'Informatique, CEA Saclay, 91191 Gif-sur-Yvette Cedex, France

${ }^{6}$ Institut d'Investigación per a la Gestío Integrada de les Zones Costaneres (IGIC) - Universitat Politècnica de València. C/Paranimf, 1., 46730 Gandia, Spain
$7,739-756,2010$

Rapid subduction in the deep North

Western

Mediterranean

J. A. Aguilar et al.

Title Page

Abstract

Introduction

Conclusions

References

Tables

Figures

14

4

Back

Close

Full Screen / Esc

Printer-friendly Version

Interactive Discussion 
${ }^{7}$ FOM Instituut voor Subatomaire Fysica Nikhef, Science Park 105, 1098 XG Amsterdam,

The Netherlands

${ }^{8}$ CPPM - Centre de Physique des Particules de Marseille, CNRS/IN2P3 et Université de la Méditerranée, 163 Avenue de Luminy, Case 902, 13288 Marseille Cedex 9, France

${ }^{9}$ APC - Laboratoire AstroParticule et Cosmologie, UMR 7164 (CNRS, Université Paris 7 Diderot, CEA, Observatoire de Paris) 10, rue Alice Domon et Léonie Duquet 75205 Paris Cedex 13, France

${ }^{10}$ LAM - Laboratoire d'Astrophysique de Marseille, CNRS/INSU et Université de Provence, Traverse du Siphon - Les Trois Lucs, BP 8, 13012 Marseille Cedex 12, France

${ }^{11}$ Dipartimento di Fisica dell'Università e Sezione INFN, Viale Berti Pichat 6/2, 40127 Bologna, Italy

${ }^{12}$ INFN - Sezione di Bologna, Viale Berti Pichat 6/2, 40127 Bologna, Italy

${ }^{13}$ Dipartimento di Fisica dell'Università La Sapienza, P. le Aldo Moro 2, 00185 Roma, Italy

${ }^{14}$ INFN - Sezione di Roma, P. le Aldo Moro 2, 00185 Roma, Italy

${ }^{15}$ Dipartimento di Fisica dell'Università, Largo B. Pontecorvo 3, 56127 Pisa, Italy

${ }^{16}$ INFN - Sezione di Pisa, Largo B. Pontecorvo 3, 56127 Pisa, Italy

${ }^{17}$ INAF-IASF, via P. Gobetti 101, 40129 Bologna, Italy

${ }^{18}$ GéoSciences Azur, CNRS/INSU, IRD, Université de Nice Sophia-Antipolis, Université Pierre et Marie Curie - Observatoire Océanologique de Villefranche, BP48, 2 quai de la Darse, 06235 Villefranche-sur-Mer Cedex, France

${ }^{19}$ INFN - Sezione di Bari, Via E. Orabona 4, 70126 Bari, Italy

${ }^{20}$ INFN - Laboratori Nazionali del Sud (LNS), Via S. Sofia 44, 95123 Catania, Italy

${ }^{21}$ Direction des Sciences de la Matière - Institut de recherche sur les lois fondamentales de I'Univers - Service de Physique des Particules, CEA Saclay, 91191 Gif-sur-Yvette Cedex, France

${ }^{22} \mathrm{COM}$ - Centre dOcéanologie de Marseille, CNRS/INSU et Université de la Méditerranée, 163 Avenue de Luminy, Case 901, 13288 Marseille Cedex 9, France

${ }^{23}$ Université Paris-Sud 11 - Département de Physique - 91403 Orsay Cedex, France

${ }^{24}$ Dipartimento di Fisica dell'Università, Via Dodecaneso, 16146 Genova, Italy

\section{OSD}

$7,739-756,2010$

\section{Rapid subduction in the deep North Western \\ Mediterranean}

J. A. Aguilar et al.

\section{Title Page}

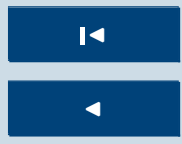

$>1$

Back

Close 
${ }^{25} \mathrm{IPHC}$ - Institut Pluridisciplinaire Hubert Curien, Université de Strasbourg et IN2P3/CNRS, 23 rue du Loess, BP 28, 67037 Strasbourg Cedex 2, France

${ }^{26}$ Royal Netherlands Institute for Sea Research (NIOZ), Landsdiep 4, 1797 SZ't Horntje (Texel), The Netherlands

${ }^{27}$ Kernfysisch Versneller Instituut (KVI), University of Groningen, Zernikelaan 25, 9747 AA Groningen, The Netherlands

${ }^{28}$ Universiteit Utrecht, Faculteit Betawetenschappen, Princetonplein 5, 3584 CC Utrecht, The Netherlands

${ }^{29}$ Universteit van Amsterdam, Institut voor Hoge-Energiefysika, Science Park 105, 1098 XG Amsterdam, The Netherlands

${ }^{30}$ Dipartimento di Fisica ed Astronomia dell'Università, Viale Andrea Doria 6, 95125 Catania, Italy

${ }^{31}$ University of Wisconsin - Madison, 53715, WI, USA

${ }^{32}$ Institute for Space Sciences, 77125 Bucharest, Mágurele, Romania

${ }^{33}$ ITEP - Institute for Theoretical and Experimental Physics, B. Cheremushkinskaya 25, 117218 Moscow, Russia

${ }^{34}$ Laboratoire d'Oceanographie Physique et de Biogeochimie (LOPB), CNRS UMR 6535, Université de la Mediterranée, Centre d'Oceanologie de Marseille, Antenne de Toulon c/o IFREMER, BP 330, 83507 La Seyne, France

${ }^{35}$ University of Leiden, The Netherlands

*on leave from: DESY, Platanenallee 6, 15738 Zeuthen, Germany

**not member of the ANTARES collaboration, but contributor to this paper

Received: 1 February 2010 - Accepted: 12 March 2010 - Published: 24 March 2010

Correspondence to: H. van Haren (hans.van.haren@ nioz.nl)

Published by Copernicus Publications on behalf of the European Geosciences Union.

OSD

$7,739-756,2010$

\section{Rapid subduction in the deep North Western Mediterranean}

J. A. Aguilar et al.

Title Page

Abstract

Introduction

Conclusions

References

Tables

Figures

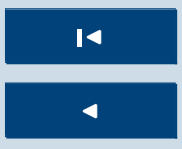

$>$ I

Back

Close

Full Screen / Esc

Printer-friendly Version

Interactive Discussion 


\section{Abstract}

An Acoustic Doppler Current Profiler (ADCP) moored at the deep-sea ANTARES neutrino telescope site near Toulon, France, measured downward vertical currents of amplitudes up to $0.03 \mathrm{~m} \mathrm{~s}^{-1}$ in spring 2006. The currents were accompanied by enhanced

5 levels of acoustic reflection by a factor of about 10 and by horizontal currents reaching $0.35 \mathrm{~m} \mathrm{~s}^{-1}$. These observations coincided with high levels of bioluminescence detected by the telescope. Although during winter 2006 deep dense-water formation occurred in this area, episodes of high levels of suspended particles and large vertical currents continuing into the summer are not direct evidence of this process. It is hypothesized umn $(2500 \mathrm{~m})$ within a few days, is local convection, triggered by small-mesoscale phenomena, such as meanders including a bipolar vortex, linked with boundary current instabilities.

\section{Introduction}

15 The ANTARES detector is designed to search for high-energy neutrinos coming from galactic and extra-galactic astrophysical sources. The detection principle is based on the collection of Cherenkov photons induced by relativistic charged particles, produced in neutrino interactions, using a 3-D-array of about 900 sensitive optical sensors, PhotoMultiplier Tubes (PMTs) (Amram et al., 2002). The PMTs, together with electronics, are integrated into Optical Modules (OMs) on 12 mooring lines between about 1900 and $2400 \mathrm{~m}$ in the Mediterranean Sea. An extra line is used for seismic and oceanographic observations including those on water motions, marine biology and sedimentology. The telescope is at great depths, mainly to have the water act as a shield for sunlight and cosmic rays, and also to avoid large levels of bioluminescence. In general, bioluminescent organisms are progressively less abundant at greater depths (Vinogradov, 1961). Their presence in the Mediterranean Sea is a factor of about 10 less abundant than,
OSD

7, 739-756, 2010

\section{Rapid subduction in the deep North Western Mediterranean}

J. A. Aguilar et al.
Abstract

Conclusions

Tables

14

4

Back
Title Page

\section{Full Screen / Esc}

Printer-friendly Version

Interactive Discussion 
e.g., parts of the North-Atlantic Ocean. In the Mediterranean values may differ by more than a factor of 10 as a function of time, location and depth (Priede et al., 2008).

The ANTARES site is off the French Provençal coast, close to the base of the steep continental slope (Fig. 1). A $40 \mathrm{~km}$ long electro-optical cable provides power and the 5 connection for data transmission to and from a shore station (Aguilar et al., 2007). The Northern Current (NC) flows counter-clockwise along the boundary slopes of the Ligurian and Provençal subbasins and is $\mathrm{O}(10) \mathrm{km}$ wide. As the $\mathrm{NC}$ is meandering, its rim skims over the ANTARES site. The NC borders the area of dense water formation in the subbasin (Crépon et al., 1982, 1989). As a result, this site offers oceanographers 10 excellent opportunities to study details of water motions, sediment transport and marine biology for long periods of time in the sea interior just off a continental slope. Here, we report on Acoustic Doppler Current Profiler ADCP-data (RDI, 1992) measuring echo intensity and current in all three Cartesian components: East-West (u), North-South (v), vertical (w), including periods of large persistent downward w, "subduction".

15 In the western basin of the Mediterranean, two physical processes can exist, characterized by downward $\mathrm{w}$ having $\mathrm{O}\left(10^{-2} \mathrm{~m} \mathrm{~s}^{-1}\right)$ surface-to-bottom amplitudes (Millot, 1999). Both can affect the ANTARES site: i) deep dense water convection due to evaporation and cooling of near-surface waters mixing with intermediate waters below, which is predominantly known to occur off the shelf of the Gulf of Lions (GoL), in the Provençal subbasin, "MEDOC"-area, and in the Ligurian subbasin (e.g., Voorhis and Webb, 1970; Gascard, 1973), ii) convection due to frontal zones and mesoscale eddies, such as occurring in the Algerian subbasin (van Haren et al., 2006). In both processes, the larger amplitude downward motions are found in areas of smaller horizontal extent than those of the upward motions. The former are typified by $\mathrm{O}\left(10^{2}-10^{3} \mathrm{~m}\right)$ horizontal 25 radius for downward motion "plumes" and 10-100 times larger upward motion areas (Marshall and Schott, 1999). The latter are typified for $\mathrm{O}\left(10^{5} \mathrm{~m}\right)$ radius mesoscale eddies by strong downward currents in an $\mathrm{O}\left(10^{3} \mathrm{~m}\right.$ ) wide rim around its perimeter (van Haren et al., 2006). So far, no direct observations have been reported of the effects on deep biomass by such vertical currents, but a patch of elevated bioluminescence was
OSD

7, 739-756, 2010

\section{Rapid subduction in the deep North Western Mediterranean}

J. A. Aguilar et al.

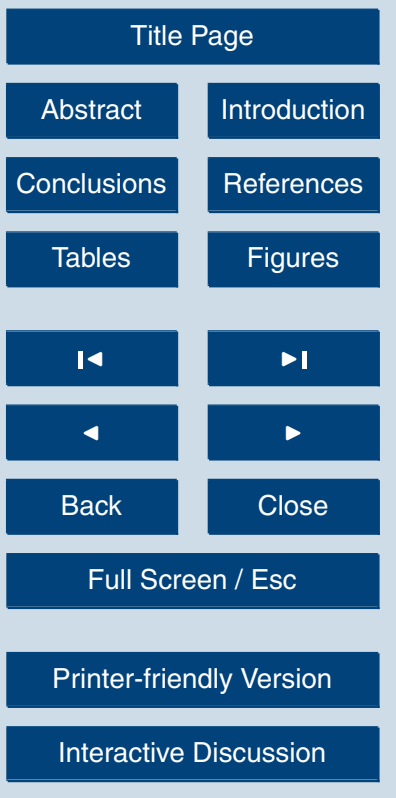


observed at about $1000 \mathrm{~m}$ underneath a mesoscale eddy in the Atlantic (Heger et al., 2008).

In the Ligurian subbasin, water motions show a seasonal variation, with mesoscale horizontal current speeds up to $0.5 \mathrm{~m} \mathrm{~s}^{-1}$ in winter compared to $\mathrm{O}\left(10^{-2}\right) \mathrm{m} \mathrm{s}^{-1}$ in 5 summer (Taupier-Letage and Millot, 1986). The larger-scale NC is directed counterclockwise and driven by buoyancy and Coriolis forces (Crépon et al., 1989). Generally in January, the NC can become baroclinically unstable with intense mesoscale activity reaching from the surface to the bottom. The NC forms waves of typical horizontal extent $\mathrm{O}\left(10^{4}-10^{5} \mathrm{~m}\right)$ with a phase speed relative to the upper layer flow $\mathrm{O}\left(10^{-1} \mathrm{~m} \mathrm{~s}^{-1}\right)$ 10 or less. Due to coupling with lower layer motions the wave propagation is almost stationary with respect to the continental slope (Griffiths and Pearce, 1985). Along the NC-border, enhanced levels of near-surface phytoplankton grow in spring and may be transported downward along the front, although evidence was so far limited to the upper few $100 \mathrm{~m}$ (e.g., Boucher et al., 1987; Gorski et al., 2002). Presently unknown is

15 the influence of the NC in transporting downward other suspended materials including zooplankton to great depths. The NC can also cause variability in horizontal motions of water masses past the ANTARES site.

\section{Data}

In spring 2005, the ANTARES Collaboration deployed and operated a so-called Mini 20

$06^{\circ} 10^{\prime} \mathrm{E}, 2475 \mathrm{~m}$ water depth (Aguilar et al., 2006) (Fig. 1). In March 2006 the first detector line became operational (Ageron et al., 2009). The MILOM consisted of an instrumented releasable anchor and of three storeys located at 100, 117 and $169 \mathrm{~m}$ above the sea bed. It was equipped with four OMs: a triplet of OMs on the middle storey and a single OM on the upper storey. A downward-looking $300 \mathrm{kHz}$, four-beam Teledyne RDI-ADCP was mounted on the upper storey. In this apparatus the beam slant is $20^{\circ}$ to the vertical. This leads to current estimates that are averages over
OSD

$7,739-756,2010$

\section{Rapid subduction in the deep North Western Mediterranean}

J. A. Aguilar et al.

\section{Title Page}

\section{Full Screen / Esc}

Printer-friendly Version

Interactive Discussion 
horizontal beam spreads of $3-80 \mathrm{~m}$ as a function of the vertical range. As the ADCP operates a redundant 4th beam, it offers an extra "error" velocity (e) that is composed of the difference between two w's estimated from the independent beam pairs. Thus, reasonable estimates are obtained for errors in $w$ that include horizontal current inho5 mogeneities over the beam spread and effects of ADCP's tilt- and heading variations.

As ADCPs rely completely on the reflection of sound on "particles" in the water, larger than about $0.003 \mathrm{~m}$ at $300 \mathrm{kHz}$ (RDI, 1992), they sample variations in these reflections as "echo intensity" (I). Part of the I-variation with depth is the inevitable acoustic energy loss in water. A simple method to correct for sound loss is the computation of a "relative 10 echo intensity", $d l=I-I_{\min }$, by subtracting the minimum $I_{\min }$ from the original signal at each depth. A single-frequency instrument cannot be used to distinguish the cause of variations in dl with time. The origin of variations ranges from changes in shape and species to number of particles. Most often however, variations in dl imply variations in the number of particles passing through the beams. A $300-\mathrm{kHz}$ ADCP is sensitive to 15 particles like large suspended flocs of material and especially zooplankton that have sizes $>10^{-3} \mathrm{~m}$, or larger animals. It is not sensitive to bacteria and phytoplankton, which have typical sizes $\mathrm{O}\left(10^{-5}-10^{-4} \mathrm{~m}\right)$ or less.

The ADCP sampled data-ensembles in 50 vertical bins of $2.5 \mathrm{~m}$ every $10 \mathrm{~min}$. The shoreward data-transport was frequently interrupted (Fig. 2) especially in the first year.

\section{Observations}

In March 2006, the PMTs counting rates, which at low levels are mainly due to ${ }^{40} \mathrm{~K}$ decay and to bioluminescent bacteria, suddenly increased by a factor of 10 or more (Fig. 2a). Low levels are observed before day 69 and after day 170 . Sudden increases are apparent for 30 days after day 69 and high levels are maintained until line 1 (Ageron et al., 2009). An increase in counting rate is usually attributed to larger levels of bioluminescence.

OSD

$7,739-756,2010$

\section{Rapid subduction in the deep North Western Mediterranean}

J. A. Aguilar et al.

\section{Title Page}

\section{Full Screen / Esc}

Printer-friendly Version

Interactive Discussion 
The ADCP's dl suddenly increased by a factor of about 10 on day 69 (Fig. 2b). Relatively large acoustic reflections occurred until day 190, and episodically later in the year. However, it is noted that optical and acoustic data may imply variations of different origin. The former are sensitive to variations due to distributed light sources, 5 such as luminescent bacteria or zooplankton species. The latter is mostly sensitive to echos due to accumulation of zooplankton and higher order species, not necessarily light-emitting objects. Associated with the increase in dl are: a doubling in current amplitude, $|\mathbf{U}|$, (Fig. 2c) and a large downward w (Fig. 2d). Aside from the period between days 70 and 100 of enhanced dl, large negative $w$ and large $|\mathbf{U}|$, periods of 10 typically 10-30 days of similar but slightly weaker absolute values are observed later in the year as well, e.g., days 220-230 and 285-300. Variations with time may be more clearly seen in series from a particular depth (Fig. 3). Large negative w and larger $\mathrm{dl}$ and $|\mathbf{U}|$ are occasionally accompanied by increases in temperature, but the correlation is ambiguous despite the tendency of large $|\mathbf{U}|$ with small $T$ (Fig. 3a). The

measurement of e shows that it has a mean of about zero and standard deviation of noise of $0.002 \mathrm{~m} \mathrm{~s}^{-1}$ (Fig. 3c). The observed $\mathrm{w}$ are systematically negative throughout the year. As a result, current inhomogeneities over the beam spread are not causing any negative bias in $\mathrm{w}$ and its apparent noise is mostly due to high-frequency internal waves and small-scale convection.

Focusing on the first half of 2006, it is seen that variations in negative $w$ and increased $\mathrm{dl}$ and $|\mathbf{U}|$ also occur at shorter periods of 1-10 days (Fig. 3). From day 70 to 80 , the mean downward motion was about $0.01 \mathrm{~m} \mathrm{~s}^{-1}$ and regularly exceeded $0.025 \mathrm{~m} \mathrm{~s}^{-1}$, or $2000 \mathrm{~m} \mathrm{day}^{-1}$. Particles can be transported from the surface to the bottom within 1-3 days by this subduction if extrapolated over the water column, due to its persistence with time. The w contain a lot of high-frequency variations that are not noise, but internal waves near the buoyancy frequency. It is noted that these $w$ are measured close to the sea bottom and larger amplitudes are expected higher-up. Such large downward motions cannot be associated with sinking particles like heavy diatoms and faecal pellets, whose speeds are 1-2 orders of magnitude smaller (Passow, 1991;
OSD

$7,739-756,2010$

\section{Rapid subduction in the deep North Western Mediterranean}

J. A. Aguilar et al.

\section{Title Page}


Lampitt et al., 1993). Also they cannot be associated with zooplankton migration, which has the following characteristics. It moves at such speeds, but down and up, in various cycles including a diurnal and a seasonal cycle, in the latter going up in spring (van Haren, 2007).

5 Similar, although less intense, variations later in the record also can cause vertical transports across at least $1000 \mathrm{~m}$ and maybe the entire water column, assuming continuity of vertical currents. Due to warming from May onwards the stratification prevents any deep convection, so that this process definitely cannot explain large autumnal downward currents. Similarly, cascading events in nearby canyons transporting 10 debris down are not expected other than in winter and during short periods $\mathrm{O}$ (days) (Khripounoff et al., 2009).

Progressive Vector Diagrams (PVDs) constructed via time integration of horizontal particle velocities using the deep ADCP data show predominant westward "displacement" between days 69 and 79, preceded by northward and followed by southward displacements (Fig. 4a). Although ambiguous, this could be interpreted as due to the passage of a mesoscale meander or clockwise eddy passing with its core between the ANTARES site and the coast during westward propagation with the prevailing NC, such as observed previously (Crépon et al., 1982). Generally, the baroclinically unstable, meandering NC passes inshore of the ANTARES site (e.g., Fig. 4b). Particularly on day 69 we observe a strong baroclinic instability forming a vortex pair or dipole just to the East of the ANTARES site (Fig. 4b), with a seaward jet. The dimensions are $40 \times 80 \mathrm{~km}$, about twice the amplitude and wavelength of typical NC-instabilities that are visible to the West of the dipole and which occur at 10-20 days intervals. The size of the dipole compares well with previous observations affecting surface plankton in the Atlantic Ocean (Gower et al., 1980). Due to cloudiness not many good satellite images were obtained the following days, but the seaward flowing jet seemed more or less stationary over the ANTARES site for at least a fortnight. In addition, the active dipole developed connection with a surprisingly northward extent of mesoscale eddies in the central basin that finally touched the NC at the ANTARES site (Fig. 4c).
OSD

$7,739-756,2010$

\section{Rapid subduction in the deep North Western Mediterranean}

J. A. Aguilar et al.

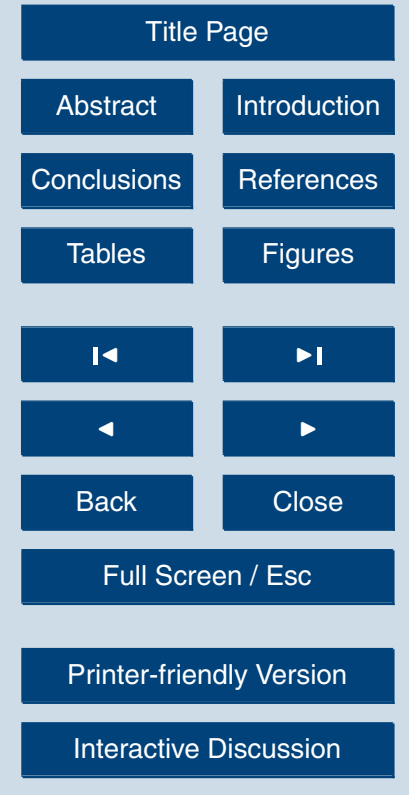


Our observations compare to some extent with models on dipoles, which have nearzero phase speed due to their interaction with the sheared current deep below (Griffiths and Pearce, 1985; Crépon et al., 1989). As a result, a particular area can receive persistent vertical flux of material during the lifetime of a jet or mesoscale meander 5 or eddy. Later in the ADCP-record indication is found for more meanders or eddies, associated with times of large downward vertical currents. The PVDs show eddies of a clockwise nature, but it is noted that eddy interpretation from PVD can be ambiguous when no other information is available.

\section{Discussion}

10 The beginning of 2006 was characterized by particularly strong convection observed in the GoL- and MEDOC-areas during two major periods, January and March/April, and which lasted well into spring (Durrieu de Madron, personal communication, 2008). However, although MEDOC-dense water formation may extend to the East into the Ligurian subbasin, it is unlikely that the present observed rapid subduction is directly 15 associated with either of these water masses and even with local deep convection, for a number of reasons: i) GoL dense water cascading downwards from the shelf will follow the Spanish coast towards the Balearic Islands due to deflection by the rotation of the earth and hampered by deep convection in the MEDOC region above the abyssal plain, ii) deep convection occurs also in the Ligurian subbasin which showed anomalous high 20 salinity and temperature in 2006 (Schroeder et al., 2008; Smith et al., 2008) whilst no persistent T-excess is found in the present record, iii) downward motions are observed throughout the year, not only in winter/early spring. The NC is a permanent current, as is its meandering activity, although modulated by seasonal variation and (re)inforced by dense water formation (Crépon et al., 1989). The meandering NC-front is a good 25 candidate to cause temporal variations in current and dl at the ANTARES site all year long, when forced to great depths.
OSD

7, 739-756, 2010

Rapid subduction in the deep North Western Mediterranean

J. A. Aguilar et al.

Title Page

Abstract Introduction

Conclusions

Tables References Figures

14

4

Back

Close

Printer-friendly Version

Interactive Discussion 
As a result, and given the support by sea-surface satellite images, active mesoscale motions could cause the observed large downward motions. As such motions are generated via instabilities of the coastal NC-system in response to atmospheric forcing above the deep open subbasin, they follow periods of exceptional dense water forma5 tion and last for months.

The present acoustical observations support the optical observations of the ANTARES array that large amounts of particles are transported downward from higher up, possibly from the surface to the bottom, resulting sometimes in particularly high counting rates in the PMTs. As both acoustics and optical sensors respond at the 10 same time and because acoustics are insensitive to bacteria, an important contribution to bioluminescence can be ascribed to crustacea and zooplankton, or, perhaps though unlikely, to large suspended material carrying luminescent bacteria. This provides unique indications that the sea replenishes fresh organic material to the abyssal plains when mesoscale meanders or eddies appear, not just over the ANTARES site, 15 but anywhere where unstable currents occur.

Acknowledgements. Satellite images are NASA/MODIS, processed by Ifremer and available on the Nausicaa/MarCoast server. The authors acknowledge the financial support of the funding agencies: Centre National de la Recherche Scientifique (CNRS), Commissariat á l'Energie Atomique (CEA), Commission Européenne (FEDER fund and Marie Curie Program), Région 20 Alsace (contrat CPER), Région Provence-Alpes-Côte d'Azur, Département du Var and Ville de La Seyne-sur-Mer, in France; Bundesministerium für Bildung und Forschung (BMBF), in Germany; Istituto Nazionale di Fisica Nucleare (INFN), in Italy; Stichting voor Fundamenteel Onderzoek der Materie (FOM), Nederlandse organisatie voor Wetenschappelijk Onderzoek (NWO), in the Netherlands; Federal Agency for Science and Innovation (Rosnauka), in Russia; 25 National Authority for Scientific Research (ANCS) in Romania; Ministerio de Ciencia e Innovación (MICINN), in Spain. We also acknowledge the technical support of Ifremer, AIM and Foselev Marine for the sea operation and the CC-IN2P3 for the computing facilities.

OSD

$7,739-756,2010$

\section{Rapid subduction in the deep North Western Mediterranean}

J. A. Aguilar et al.

\section{Title Page}

\section{Full Screen / Esc}

Printer-friendly Version

Interactive Discussion 


\section{References}

Ageron, M. et al. (ANTARES collaboration): Performance of the first ANTARES detector line, Astropart. Phys., 31, 277-283, 2009.

Aguilar, J. A. et al. (ANTARES collaboration): First results of the instrumentation line for the deep-sea ANTARES telescope, Astropart. Phys., 26, 314-324, 2006.

Aguilar, J. A. et al. (ANTARES collaboration): The data acquisition for the ANTARES telescope, Nucl. Instr. Meth. Phys. Res., A570, 107-116, 2007.

Amram, P. et al. (ANTARES collaboration): The ANTARES optical module, Nucl. Instr. Meth., Phys. Res., A484, 369-383, 2002.

Boucher, J., Ibanez, F. and Prieur, L.: Daily and seasonal variations in the spatial distribution of zooplankton populations in relation to the physical structure in the Ligurian Sea front, J. Mar. Res., 45, 133-173, 1987.

Crépon, M., Wald, L. and Monget, J. M.: Low-frequency waves in the Ligurian Sea during December 1977, J. Geophys. Res., 87, 595-600, 1982.

15 Crépon, M., Boukhtir, M., Barnier, B., and Aikman III, F.: Horizontal ocean circulation forced by deep-water formation. Part I: an analytical study, J. Phys. Oceanogr., 19, 1781-1792, 1989.

Gascard, J.-C.: Vertical motions in a region of deep water formation, Deep-Sea Res., 20, $1011-$ 1027, 1973.

Gorski, J., Prieur, L., Taupier-Letage, I., Stemmann, L. and Picheral, M.: Large particulate matter in the Western Mediterranean 1. LPM distribution related to mesoscale hydrodynamics, J. Mar. Sys., 33-34, 289-311, 2002.

Gower, J. F. R., Denman, K. L. and Holyer, R. L.: Phytoplankton patchiness indicates the fluctuation spectrum of mesoscale oceanic structure, Nature, 288, 157-159, 1980.

Griffiths, R. W. and Pearce, A. F.: Instability and eddy pairs on the Leeuwin Current south of Australia, Deep-Sea Res., 32, 1511-1534, 1985.

Heger, A., leno, E. N., King, N. J., Morris, K. J., Bagley, P. M. and Priede, I. G.: Deep-sea pelagic bioluminescence over the Mid-Atlantic Ridge, Deep-Sea Res. Pt. II., 55, 126-136, 2008.

Khripounoff, A., Vangriesheim, A., Crassous, P. and Etoubleau, J.: High-frequency of sediment gravity flow events in the VAR submarine canyon (Mediterranean Sea), Mar. Geol., 263, 1-6, 2009.
OSD

7, 739-756, 2010

\section{Rapid subduction in the deep North Western Mediterranean}

J. A. Aguilar et al.

\section{Title Page}

Abstract Introduction

Conclusions

References

Tables

Figures

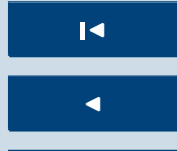

$\rightarrow 1$

Back

Close

Printer-friendly Version

Interactive Discussion 
Lampitt, R. S., Hillier, W. R. and Challenor, P. G.: Seasonal and diel variation in the open ocean concentration of marine snow aggregates, Nature, 362, 737-739, 1993.

Marshall, J. and Schott, F.: Open-ocean convection: observations, theory, and models, Rev. Geophys., 37, 1-64, 1999.

5 Millot, C.: Circulation in the Western Mediterranean Sea, J. Mar. Sys., 20, 423-442, 1999.

Passow, U.: Species-specific sedimentation and sinking velocities of diatoms, Mar. Biol., 108, 449-455, 1991.

Priede, I. G., Jamieson, A., Heger, A., Craig, J., and Zuur, A.: The potential influence of bioluminescence from marine animals on a deep-sea underwater neutrino telescope array in the

10 Mediterranean sea, Deep-Sea Res. Pt. I, 55, 1474-1483, 2008.

RDI: A practical primer, RD-Instruments, San Diego, USA, 1992.

Schroeder, K., Ribotti, A., Borghini, M., Sorgente, R., Perilli, A., and Gasparini, G. P.: An extensive Western Mediterranean deep water renewal between 2004 and 2006, Geophys. Res. Lett., 35, L18605, doi:10.1029/2008GL035146, 2008.

Smith, R. O., Bryden, H. L., and Stansfield, K.: Observations of new western Mediterranean deep water formation using Argo floats 2004-2006, Ocean Sci., 4, 133-149, 2008, http://www.ocean-sci.net/4/133/2008/.

Taupier-Letage, I. and Millot, C.: General hydrodynamic features in the Ligurian Sea inferred from the DYOME experiment, Oceanol. Acta, 9, 119-132, 1986.

20 van Haren, $\mathrm{H}$.: Monthly periodicity in acoustic reflections and vertical motions in the deep ocean, Geophys. Res Lett., 34, L12603, doi:10.1029/2007GL029947, 2007.

van Haren, H., Millot, C., and Taupier-Letage, I.: Fast deep sinking in Mediterranean eddies, Geophys. Res. Lett., 33, L04606, doi:10.1029/2005GL025367, 2006.

Vinogradov, M. E.: Feeding of the deep-sea zooplankton. Rapp. P. V. Réun. Cons. Int. Explor. 25 Mer, 153, 114-120, 1961.

Voorhis, A. D. and Webb, D. C.: Large vertical currents observed in a winter sinking region of the northwestern Mediterranean, Cah. océanogr., 22, 571-580, 1970.

OSD

$7,739-756,2010$

\section{Rapid subduction in the deep North Western Mediterranean}

J. A. Aguilar et al.

Title Page

Abstract

Introduction

Conclusions

References

Tables

Figures

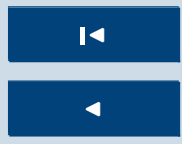

$>1$

Back

Close

Full Screen / Esc

Printer-friendly Version

Interactive Discussion 


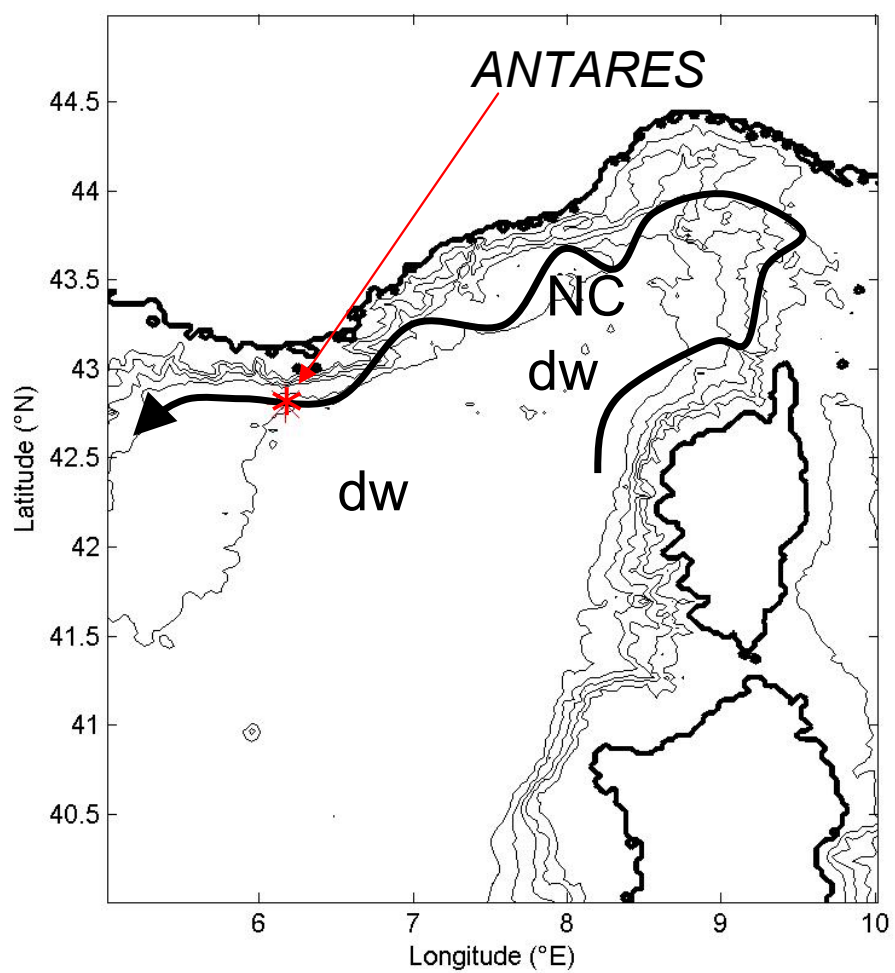

Fig. 1. ANTARES site (red star) on the northern part of the Ligurian subbasin, western basin Mediterranean, with a sketch of the Northern Current NC (solid line) and areas of dense-water formation $(\mathrm{dw})$. Isobaths every $500 \mathrm{~m}$ between $[-500,-2500] \mathrm{m}$.
OSD

$7,739-756,2010$

Rapid subduction in the deep North

Western

Mediterranean

J. A. Aguilar et al.

Title Page

Abstract

Introduction

Conclusions

References

Tables

Figures

14

4

Back

Close

Full Screen / Esc

Printer-friendly Version

Interactive Discussion 


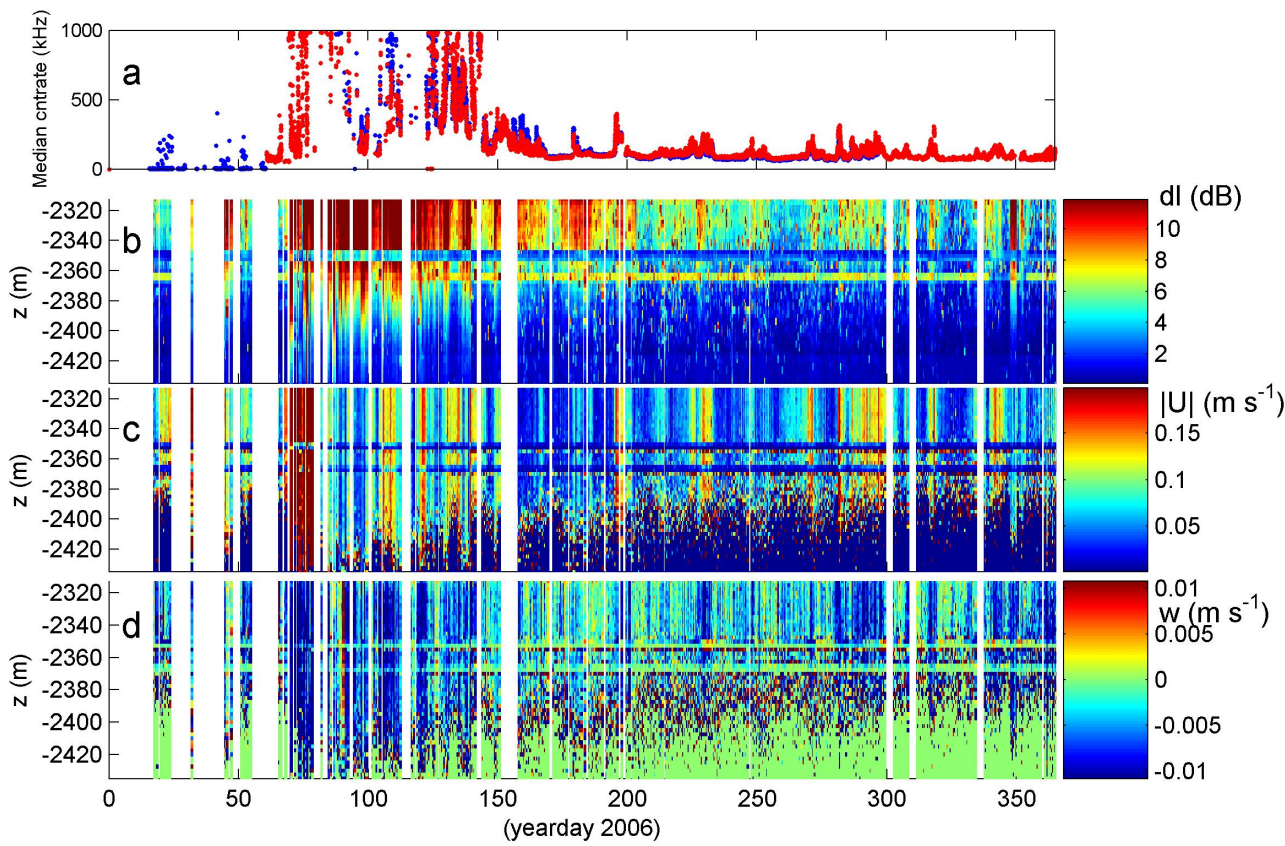

Fig. 2. (a) Optical counting rate observed $50 \mathrm{~m}$ below the ADCP at MILOM (blue) and on Line 1 (red) as a function of time. (b-d) Raw MILOM-ADCP data, time-depth series. In all panels the vertical white lines indicate absent data. The two horizontal lines at 2350 and $2365 \mathrm{~m}$ are direct sound reflections from two storeys below the ADCP. (b) Relative echo amplitude from a beam, limited to $[0,12] \mathrm{dB}$. (c) Current amplitude, between $[0,0.2] \mathrm{m} \mathrm{s}^{-1}$. (d) Vertical current, between $[-0.01,0.01] \mathrm{m} \mathrm{s}^{-1}$. In (c, d) useful data are available down to about $2390 \mathrm{~m}$, and to about $2420 \mathrm{~m}$ between days 70 and 100 when echos are large. The time convention is 1 January, 12:00 UTC = day 0.5, 2006.

OSD

$7,739-756,2010$

\section{Rapid subduction in the deep North Western \\ Mediterranean}

J. A. Aguilar et al.

Title Page

Abstract

Conclusions

Tables

1

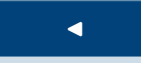

Back

Full Screen / Esc

Printer-friendly Version

Interactive Discussion 
OSD

$7,739-756,2010$

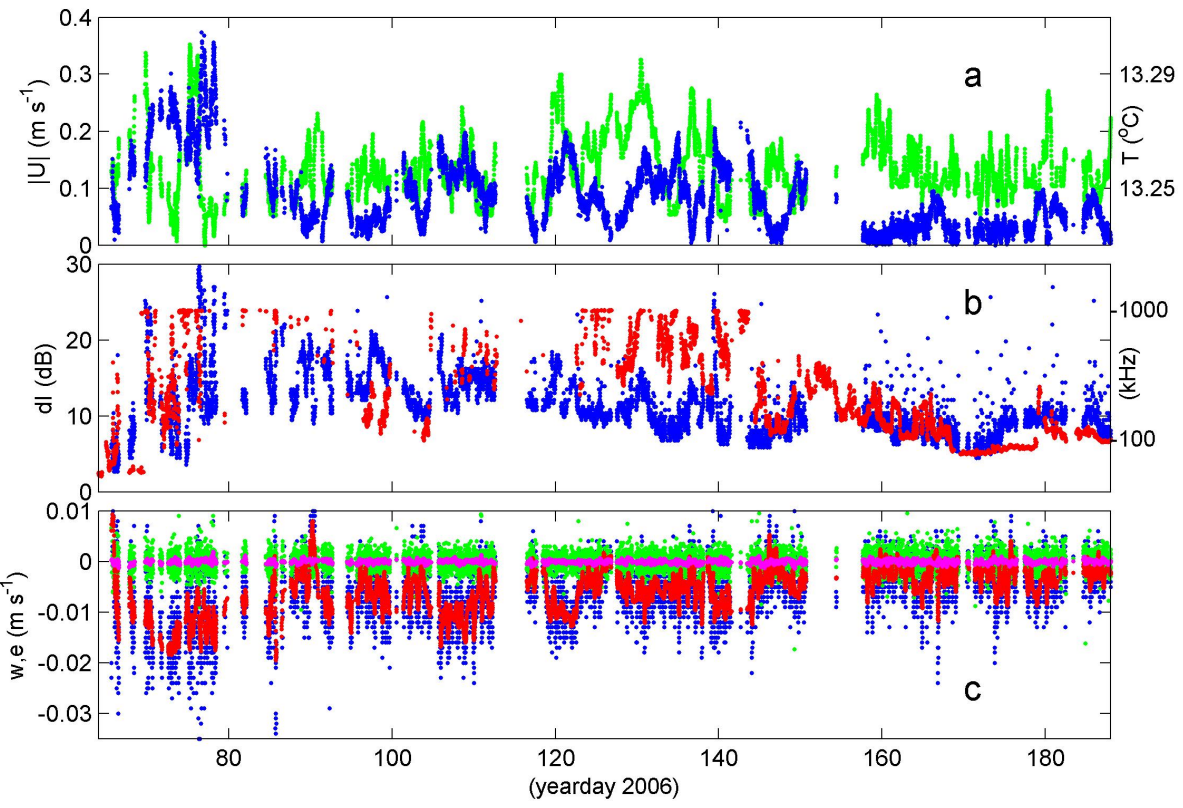

Fig. 3. (a) Horizontal current amplitude at $2320 \mathrm{~m}$ (blue; raw data) and temperature (green; smoothed) measured at the ADCP. (b) Relative sound-echo amplitude (blue; smoothed) and PMT baseline data from $2350 \mathrm{~m}$ (red). (c) Vertical current (blue: raw data; red: smoothed) and error velocity (green: raw data; purple: smoothed). Applied smoothing is using a 20-points running mean.

\section{Rapid subduction in the deep North \\ Western \\ Mediterranean}

J. A. Aguilar et al.

Title Page

Abstract

Introduction

Conclusions

References

Tables

Figures

14

4

Back

Close

Full Screen / Esc

Printer-friendly Version

Interactive Discussion 


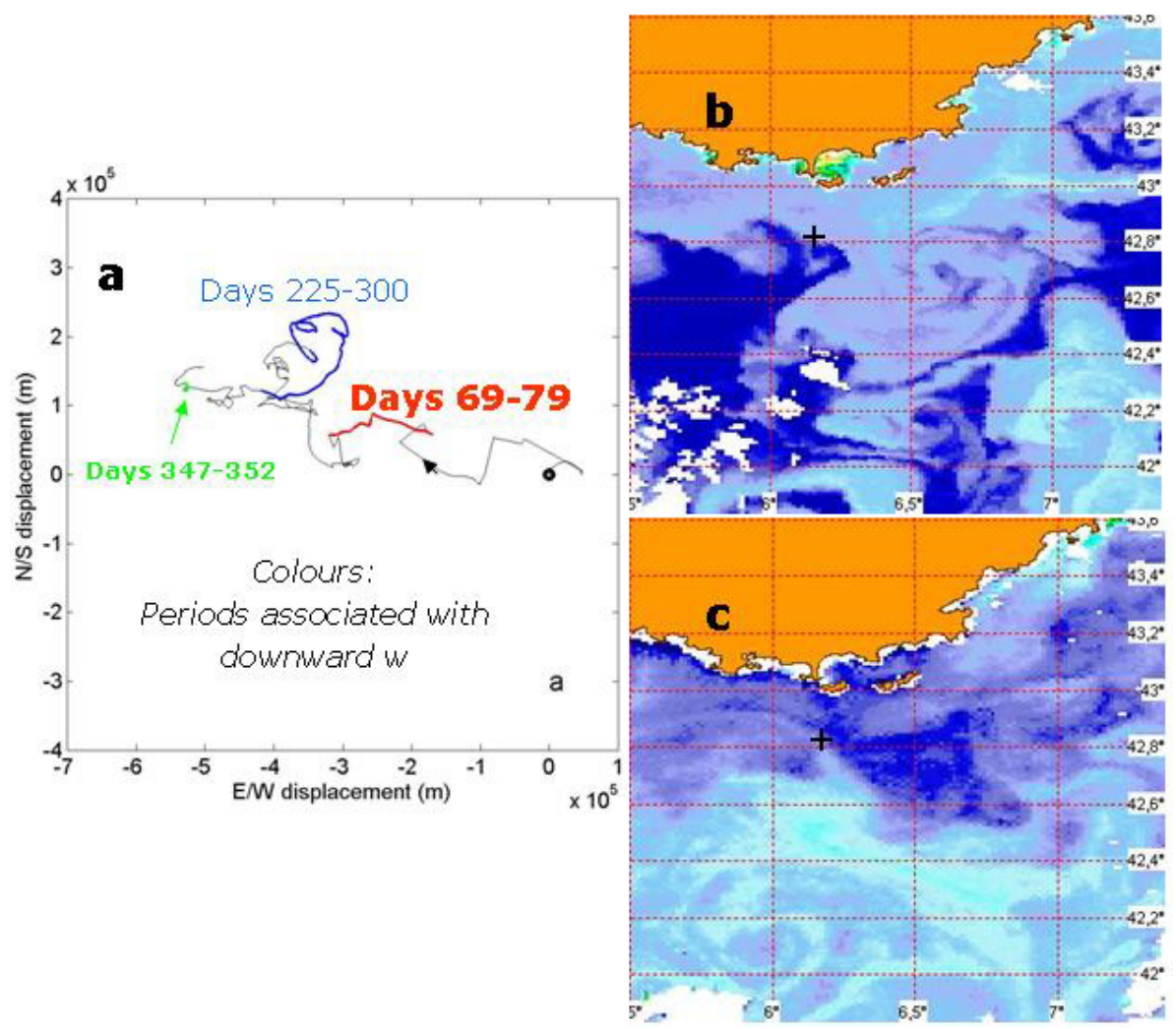

\section{Rapid subduction in the deep North Western \\ Mediterranean}

J. A. Aguilar et al.

\section{Title Page}

Abstract

Conclusions

Tables

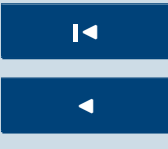

Back

Full Screen / Esc

Fig. 4. (a) Progressive Vector Diagram of integrated Eulerian horizontal currents observed at $2320 \mathrm{~m}$. In black the total 2006 -time series that start at $(0,0)$, in colours portions between the days indicated. (b) Satellite image of false-coloured near-surface chlorophyll-a on day 69. (c) As (b), but for near-surface suspended particulate matter on day 88. In (b) and (c). the ANTARES site is marked by a cross. Note the images are used qualitatively for pattern recognition.
Printer-friendly Version

Interactive Discussion 